\title{
An Investigation of the Effectiveness of Doing Sports Situation, Gender and Age Variations in Sadness Management in Children
}

\author{
Kazim Nas \\ Karamanoglu Mehmetbey University, TURKEY
}

\author{
Veysel Temel * \\ Karamanoglu Mehmetbey University, TURKEY
}

Received: July 11, 2018 - Revised: September 3, 2018 - Accepted: September 21, 2018

\begin{abstract}
This study was conducted with the aim of investigating the effect of doing sports, gender and age variables on sadness management of students. The universe of the research was 558 students (age average $=11,96 \pm 1,29$ ), including 308 female and 250 male students studying in the secondary school of in Karaman between 2017-2018 period. In addition to the personal information form prepared by the researcher as a data collection tool in the research, "Child Sadness Management Scale" developed by Zeman et al., adapted to the Turkish language by Akin et al. was used. MANOVA and ANOVA analysis were performed in the solution and interpretation of the data. At the end of the study; it can be said that the levels of Inhibition from the sadness management subdimensions of the participants are in the middle level, Emotion Regulation Coping levels are above the mid - level and DysregulatedExpression levels are low. There was a significant difference between doing sports variable of the participants and the Inhibition dimension and between the gender variable and sub-dimension of the Dysregulated-Expression, but there was no significant difference between age variable and sub-dimensions of the sadness management.
\end{abstract}

Keywords: Sports, sadness management, child.

To cite this article: Kazim, N., \& Temel, V. (2018). An investigation of the effectiveness of doing sports situation, gender and age variations in sadness management in children. European Journal of Educational Research, 7(4), 827-831. doi: 10.12973/eujer.7.4.827

\section{Introduction}

Sadness is often described in classical dictionaries as an unwanted situation or grief experienced by a loss in the past (Cagrici, 1999). Today, when we look at the evaluations of the concept of sadness, the first reaction that a person gives when he / she experiences an event that disturbs the psychological balance is a form of anxiety and sadness. The feeling that the person feels depressed and being depressed is accompanied by a diminished feeling of pleasure. (Tarhan, 2012). The reason for the sadness is the greed and greed that are shown to the tangible assets and the bodily desire, the longing for the things that are lost or can not be obtained. A person who thinks that whatever he gains from the things of the world will always be by himself, is sorry when he/she loses them. The relief from this emotion depends on the person himself. Man will be just to himself, and if he knows that all things in the world are not fixed and constant, and that the constant and constant is the reason, he will neither hope nor go after it. The person who acts like this is happy and confident and happy (Sener et al., 1983).

It is stated that the removal or reduction of sadness can be in two ways. The first of them will be able to protect him from the sadness by taking measures against sadness so that it will be as small as possible, even if it happens or doesn't happen yet. The second is to remove the whole or the maximum possible amount when it happens and to take measures to make it less and weaker even if it does not happen or happens (Karaman, 2004).

Sadness, there are also physiological effects on human life. In the case of sadness, the brain consumes chemistry related to happiness fast, and if this state continues for a certain period, the happiness hormone, called as serotonin, decreases in the brain. The second phase, in which a person who cannot compensate for his sorrow in three days, is described as a six-week process. A person who gets sad to disrupt his daily life during a month and a half should receive expert help in this regard (Tarhan, 2012).

Sadness is a key factor for the human. It gives the individual a lot of experience in improving himself / herself. There is much to learn from human experience. It is necessary to accept him as a guest. We treated sadness and melancholy, and

\footnotetext{
* Corresponding author:

Veysel Temel, Karamanoglu Mehmetbey University, School of Physical Education and Sports, Karaman, Turkey.

Email: veyseltemel@kmu.edu.tr
} 
today many literary and philosophical products did not emerge. There is much to learn from human experience (Sayar, 2012).

Sadness and happiness are an integral part of our life. It makes us strong in this life. The fact that a person who acquires goods for this reason is unable to obtain what he wants to peel off his goods or to get things he wants is in fact based on Kindi. So we should not aim for ourselves worthless things. As previously stated, sadness is worthless. According to Kindi, the one who takes something worthless for himself is insane (Tarhan, 2012).

In addition to being a neglected issue of sadness management in children, depression is a direct link to problems such as childhood mourning (Zeman et al., 2001). When an important concept of Turkey in the literature to be screened for emotional management of mental health issues where more work life and dealt with in an organizational context (Akcay and Coruk, 2012) and often anger management (Cenkseven, 2003; Karatas, 2009), stress management (Akova and Isik , 2008), which are negative effects on social life. Although research on adult and adolescent groups is generally available, research on emotion management in children is limited. Regarding basic emotions during childhood (Johnson-Iaird and Oatley, 1989), gaining managerial skills is thought to be an important factor in reducing adverse factors in life.

Sports; it serves to develop inter-human relations and increase social participation. At the same time, it also enhances business cohesion and solidarity among people. The importance of sports in society is increasing day by day (Duman, 2009). It is a discipline that educators offer in terms of sports, person's social adaptation, mental and physical health, competition winners, the formation and development of personality, a favorite course of masses, a method used by managers to shape energy and stimulate a balanced, (Fisek, 1978). There are also many factors that influence sport participation, continuity and performance in the sport environment. Concepts such as play, health, status or performance may be important for individuals towards sport. Motivation plays an important role in the continuity of sport as well as the orientation of sport and in the success graph (Tiryaki, 2000).

\section{Method}

\section{Research Group}

The research group consists of a total of 558 students (age average $=11,96 \pm 1,29$ ), 308 female and 250 male students from secondary schools in Karaman in 2017-2018 academic year.

\section{Collection of Data}

The current available information for the purpose of the study was given in a systematic manner by searching the literature. Thus, a theoretical framework has been established. In order to evaluate the coping behaviors of secondary school students in their sadness situations, "Children's Sadness Management Scale" developed by Zeman et al. (2001) and adapted to Turkish by Akin et al. (2014) and also the personal information form to collect the participants' personal information were used.

\section{Data Collection Tools}

The data collection tools required to achieve the research objectives are given below:

\section{Personal Information Form}

A questionnaire consisting of 6 questions was prepared by the researcher in order to gather information about the personal characteristics of secondary school students and to create independent variables of the research.

\section{Child Sadness Management Scale}

Child Sadness Management Scale" was developed by Zeman et al. (2001) and adapted to the Turkish language by Akin et al. (2014). The scores obtained from between the Child Sadness Management Scale for Inhibition, Emotion Regulation Coping, Dysregulated-Expression subscales and Childhood Depression Scale were $r=.30, r=-.31, r=.32$, respectively. Internal consistency, the Cronbach alpha internal consistency coefficients were found to be .77 for the inhibition subscale, .62 for the emotional regulation subscale, and .60 for the irregular outward reflection subscale. Factor loadings range from .27 to .68. The Dysregulated-Expression consistency (Cronbach Alpha) reliability coefficient of the study was 0.78 , the emotional regulation coping internal consistency (Cronbach Alpha) reliability coefficient was 0.72 , and the inhibition dimension was 0.74 .

\section{Analysis of Data}

It has been determined that the normal distribution of the data for the child sadness management sub-dimensions (Dysregulated-Expression, Emotional Regulation Coping and Inhibition) is checked by checking the histogram to see if the normal distribution is appropriate. Gender, Age and Age * Gender * Differences in relation to partner relationship as sporting are examined. Multivariate analysis of variance (MANOVA) has been used to solve this problem. This analysis provides the opportunity to see the total relationship of the independent variables (Doing Sports, Gender and Age type) together with all dependent variables (Dysregulated-Expression, Emotional Regulation Coping and Inhibition). SPSS 21 
(Statistical Package for Social Sciences) package program was used to evaluate the data and to calculate the calculated values.

Figure 1. Histogram distribution test chart for Inhibition, Emotion Regulation Coping, Dysregulated-Expression subdimensions of children participating in the research

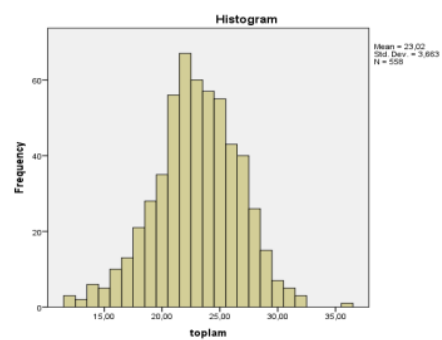

Inhibition

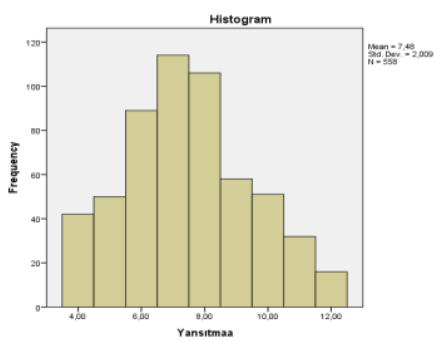

Emotion Regulation Coping

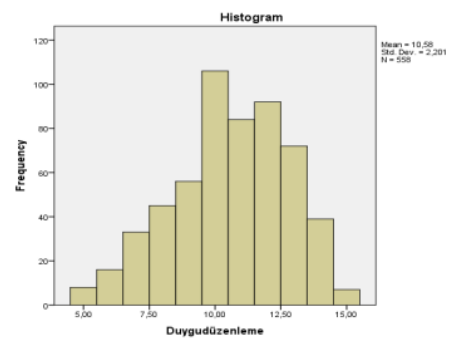

Dysregulated-Expression

From Figure 2, the histogram of Inhibition, Emotion Regulation Coping and Dysregulated-Expression was checked from child sadness management sub-dimensions. According to this, the normal distribution is reached.

\section{Results}

\section{Personal Characteristics of the Research Group}

The data and comments on the demographic characteristics of the children participating in the survey are given below.

Table 1. Demographic Characteristics of the sample group participated in the survey

\begin{tabular}{llcc}
\hline Demographic Characteristics & & n & \% \\
\hline \multirow{2}{*}{ Gender } & Female & 308 & 55.2 \\
& Male & 250 & 44.8 \\
Age & $10-12$ year old & 353 & 63.3 \\
\multirow{2}{*}{ Doing Sports Situation } & $13-15$ year old & 205 & 36.7 \\
& Yes & 293 & 52.5 \\
& No & 265 & 47.5 \\
\hline
\end{tabular}

According to Table 1, 308 people (55.2\%) are female and 250 (44.8\%) are male participants according to the gender variable. According to age of participants, 353 persons (63.3\%) were between 10 and 12 years of age while 205 persons (36,7\%) were between 13 and 15 years of age. 293 people (52.5\%) say "yes" to sports and 265 people (47.5\%) say "no".

Table 2. Participants' Results Regarding Sadness Management Total Score and Sub-Dimension Score

\begin{tabular}{lccccc}
\hline & $\mathbf{n}$ & Mean & SS & Min & Max \\
\hline Inhibition & 558 & 7.48 & 2.01 & 4.00 & 12.00 \\
Emotion Regulation Coping & 558 & 10.58 & 2.20 & 5.00 & 15.00 \\
Dysregulated-Expression & 558 & 4.95 & 1.46 & 3.00 & 9.00 \\
Total Sadness Management & 558 & 23.02 & 3.66 & 12.00 & 36.00 \\
\hline
\end{tabular}

In Table 2, average scores of the participants' sadness management point averages and sub-dimensions were examined. As a result of this review; it was found that the students who participated in the survey had a total score average of 23.02 and they were below the average. Inhibition was a low level with 7.48, Emotion Regulation Coping was mid level with 10,58 and Dysregulated-Expression was a low level with 4,95. 
Table 3: Participants' Sadness Management Level MANOVA Table

\begin{tabular}{cllccc}
\hline & & F & Hipotez df & Hata df & Sig. \\
\hline \multirow{4}{*}{ Doing Sports } & Pillai's Trace & $3.04^{\mathrm{b}}$ & 3.00 & 548.00 & .03 \\
& Wilks' Lambda & $3.04^{\mathrm{b}}$ & 3.00 & 548.00 & .03 \\
& Hotelling's Trace & $3.04^{\mathrm{b}}$ & 3.00 & 548.00 & .03 \\
& Roy's Largest Root & $3,04^{\mathrm{b}}$ & 3.00 & 548.00 & .03 \\
\hline \multirow{3}{*}{ Age } & Pillai's Trace & $.43^{\mathrm{b}}$ & 3.00 & 548.00 & .73 \\
& Wilks' Lambda & $.43^{\mathrm{b}}$ & 3.00 & 548.00 & .73 \\
& Hotelling's Trace & $.43^{\mathrm{b}}$ & 3.00 & 548.00 & .73 \\
& Roy's Largest Root & $.43^{\mathrm{b}}$ & 3.00 & 548.00 & .73 \\
\hline \multirow{3}{*}{ Gender } & Pillai's Trace & $7.42^{\mathrm{b}}$ & 3.00 & 548.00 & .00 \\
& Wilks' Lambda & $7.42^{\mathrm{b}}$ & 3.00 & 548.00 & .00 \\
& Hotelling's Trace & $7.42^{\mathrm{b}}$ & 3.00 & 548.00 & .00 \\
& Roy's Largest Root & $7.42^{\mathrm{b}}$ & 3.00 & 548.00 & .00 \\
\hline \multirow{3}{*}{ Doing Sports $*$} & $1.21^{\mathrm{b}}$ & 3.00 & 548.00 & .30 \\
Age * Gender & Pillai's Trace & $\mathbf{1 . 2 1}^{\mathrm{b}}$ & $\mathbf{3 . 0 0}$ & $\mathbf{5 4 8 . 0 0}$ &. $\mathbf{3 0}$ \\
& Wilks' Lambda & $1.21^{\mathrm{b}}$ & 3.00 & 548.00 & .30 \\
& Hotelling's Trace & $1.21^{\mathrm{b}}$ & 3.00 & 548.00 & .30 \\
\hline
\end{tabular}

There was no difference between the variables in the MANOVA table according to the participants' sporting, age and gender type variables $(\mathrm{F}(3,548)=1.21, \mathrm{p}<.05$.

Table 7: Participants' Sadness Management Level ANOVA Table

\begin{tabular}{lccccc}
\hline & Dependent Variables & df & Mean Square & F & Sig. \\
\hline \multirow{4}{*}{ Age } & Total Sadness Management & 1 & 16.740 & .552 & .458 \\
& Inhibition & 1 & .405 & .040 & .841 \\
& Emotion Regulation Coping & 1 & 1.902 & .493 & .483 \\
& Dysregulated-Expression & 1 & 4.308 & .759 & .384 \\
\hline \multirow{4}{*}{ Sports Type } & Total Sadness Management & 1 & 25.145 & .829 & .363 \\
& Inhibition & 1 & .369 & .037 & .848 \\
& Emotion Regulation Coping & 1 & 16.621 & 4.311 & $.039^{*}$ \\
& Dysregulated-Expression & 1 & 2.386 & .421 & .517 \\
\hline \multirow{4}{*}{ Gender } & Total Sadness Management & 1 & 18.260 & .602 & .439 \\
& Inhibition & 1 & 59.752 & 5.935 & $.016^{*}$ \\
& Emotion Regulation Coping & 1 & .453 & .118 & .732 \\
& Dysregulated-Expression & 1 & 7.747 & 1.366 & .244 \\
\hline \multirow{2}{*}{ Total } & Total Sadness Management & 227 & & & \\
& Inhibition & 227 & & & \\
\hline & Emotion Regulation Coping & 227 & & & \\
\hline
\end{tabular}

The main effects have been examined since there is no difference between the independent variables. According to the ANOVA table, there was a statistically significant difference in the dimension of Emotion Regulation Coping from the sadness management sub-dimensions according to the sports type variables of individual effects ( $p<.05)$. Significant differences were found in the dimension of Inhibition from sadness management sub-dimensions according to gender variable $(\mathrm{p}<.05)$.

\section{Discussion and Conclusion}

According to the results of the research conducted for the determination of sadness management in children who do and do not do sports; it was found that the dimension of the inhibition was low, the emotional regulation coping dimension and the Dysregulated-Expression dimension were higher than the average of the sadness management subscales.

It was concluded that there was no difference between the participants who participated in the research and the variables of sport, age and gender type.

According to the variation of sporting situation; it was seen that there was no meaningful difference between participants' Dysregulated-Expression and Emotion Regulation Coping dimensions from the sadness management subdimensions, but it was found that there was a significant difference between the inhibition sub-dimensions. According to this, it is understood that the students who play sports are sadder than those who do not play sports. 
According to sex variable; it was found that there was no significant difference between participants' emotional regulation coping and inhibition dimensions from the sadness management subscales, but there was a significant difference between the Dysregulated-Expression subscale. According to this, it is understood that the female participants reflect the irregularities of the sadness according to the male participants. when sadness management scores are evaluated, it is understood that there is no meaningful difference according to gender and age variables and it is parallel to the study done (Colak, Eren \& Dogan, 2017).

More work on this area couldn't be found to discuss. This is because the relevant field has made it difficult to interpret the findings that we have lacked empirical studies in the literature.

\section{Recommendations}

In the light of the findings from research, suggestions are for field workers and future research;

- Emotional management skills to be got from early ages can be improved by increasing the faith of competence and by controlling the constant loss that negatively affects life in this direction. In this context, awareness of teachers and parents should be provided.

- Since emotion management is thought to have an important place in the individual's life, empirical studies can be made on the management of basic emotions that are effective in directing the lives of individuals.

- School psychological counselors can start emotional management group studies starting from basic emotions in younger age groups.

- In the study, only the answers given by the participants were taken into account. Considering the age group, future studies may include parental and / or teacher observations in the research process.

\section{References}

Akcay, C., \& Coruk, A. (2012). Emotions and Management in Working Life: A Conceptual Review. Policy Analysis in Education, 12(1), 3-25.

Akin, A., Saricam, H. Akkus, Z., Akin, U., Bilgin, O., \& Ugur, E. (2014, 19-31 May). Adapting the Sadness Management Scale for Children to Turkish: Validity and Reliability Study. 13. Class Teacher's Congress, Kutahya.

Akova, O., \& Isik, K. (2008). Stress Management in Hotel Business: A Research in Five Star Hotel Establishments in Istanbul. The Journal of Kocaeli University Social Sciences Institute, 15(1), 17-44.

Cagrici, M. (1999). "Sadness" Mad. I.A. Istanbul: TDV Publishing.

Cenkseven, F. (2003). The Impact of the Anger Management Skills Program on the Anger and Aggressiveness Levels of the Adolescents. The Journal of Educational Science and Application, 2(4), 153-167.

Colak, T. S., Eren, G., \& Dogan, U. (2017). A Research About Trait Anxiety, Self-Efficacy, And Sadness Management Of Primary School Students. Elementary Education Online Journal, 16(1),151-160.

Duman, U. (2009). Comparison Of The Stress Levels Of Adolescents Doing Sports Or Not. (Unpublished masters thesis). Erciyes University / Institute of Health Sciences, Kayseri.

Fisek, K. (1978). Comparative Sport Management. Ankara: 19 May Youth and Sports Academy Lecture Notes.

Johnson-Iaird, P. N., \& Oatley, K. (1989). The language of emotions: An analysis of semantic field. Cognition and Emotion, $3(2), 81-123$.

Karaman, H. (2004). Mental Health (Ebu Bekir Zekeriya Er-Razi, Mental Health, Tran.). Istanbul: Iz Publishing.

Karatas, Z. (2009). The Impact of Anger Management Program Using Cognitive Behavioral Techniques to Reduce the Aggressiveness of the Adolescents. The Education Journal of Pamukkale University, 26, 12-24.

Sayar, K. (2012). Sorrow Disease. Istanbul: Timas Publishing.

Sener, A., Ismet, K., \& Cihad, T. (1983). Moral Maturation / Tehzibu'l-Moral (Ibn Miskeveyh, Moral Maturity / Tehzibu'lAhlak, Tra.). Ankara: Ministry of Culture and Tourism Publishing.

Tarhan, N. (2012). Psychology of Feelings. Istanbul: Timas Publishing.

Tiryaki, G. (2000). Sports psychology. Ankara: September Book and Publishing.

Zeman, J., Shipman, K., \& Penza-Clyve, S. (2001). Development and initial validation of The Children's Sadness Management Scale. Journal of Nonverbal Behavior, 25(3), 187-205. 